\title{
Mouse Virulence of Salmonella Strains: The Effect of Different Smooth-type O Side-chains
}

\author{
By V. V. VALTONEN \\ Department of Serology and Bacteriology, University of Helsinki and \\ the Central Public Health Laboratory (State Serum Institute), \\ Helsinki, Finland
}

(Accepted for publication I6 October 1970)

SUMMARY

A loss or reduction in the $\mathrm{O}$ side-chain material of the cell-wall lipopolysaccharide is known to abolish or reduce the virulence of Salmonella strains. The present report concerns the effect on virulence of altering the quality of smooth-type O side-chains in a basically virulent Salmonella typhimurium line. The original $r f b^{B}$ locus determining the structure of 4,12 specific repeating units was replaced either in transduction or in conjugation by the wild-type $r f b^{D}$ locus of group D (O antigens $\left.9, I 2\right)$, or $r f b^{C}$ of group C (O antigens 6,7$)$. The $\mathrm{LD}_{50}$ values of the $4,5,12$ recombinants or transductants were about $10^{5}$ and like those of the $4,5,12$ parent, whereas the LD 50 values of the $9, I 2$ transductants were about $10^{6}$, and the $\mathrm{LD}_{50}$ values of the 6,7 recombinants and transductants were over $10^{7}$. The reduced virulence of both 9,12 and 6,7 recombinants could be restored to the original level by reintroducing the $r f b^{B}$ locus into these strains through conjugation. It seems, therefore, that different kinds of $\mathrm{O}$ side-chains confer different degrees of virulence on $S$. typhimurium.

\section{INTRODUCTION}

It has long been known that the change in colony morphology from smooth to rough ( $\mathrm{S} \rightarrow \mathrm{R}$ variation), with accompanying loss of $\mathrm{O}$ agglutinating ability, greatly reduces virulence of Salmonella bacteria (Lingelsheim, 1913; Arkwright, 1927). Since the first observation in 1913, further evidence has accumulated for the importance of the structure of the $\mathrm{O}$ antigen in virulence of Salmonella strains (Roantree, 1967).

The $\mathrm{O}$ antigen - also called endotoxin or lipopolysaccharide (LPS) - forms the outermost layer in the Salmonella cell wall and contains a lipid and a polysaccharide. The latter has a core which is common to all Salmonella species, and to which are attached long $\mathrm{O}$ side-chains (Lüderitz, Jann \& Wheat, I968). The O side-chains of at least groups $\mathrm{B}, \mathrm{D}$ and $\mathrm{E}$ are polymers of several repeating units per side-chain. The sugar composition of the repeating units (the $\mathrm{O}$ side-chain) determines the $\mathrm{O}$ specificity characteristic for each Salmonella group (Fig. I).

The $S \rightarrow R$ variation is caused by mutations blocking the synthesis of the polysaccharide. The avirulent $\mathrm{R}$ forms thus have an incomplete LPS with no $\mathrm{O}$ side-chains; $r f a$ mutants are blocked in the synthesis of the core, $r f b$ in the synthesis of the repeating unit, and $r f c$ in their polymerization (Mäkelä \& Stocker, 1969). Both $r f a$ and $r f b$

Vol. 64, No. 2 was issued I April 1971 
mutants are phenotypically $\mathrm{R}$, but $r f c$ mutants have one $\mathrm{O}$-specific repeating unit per side-chain and are SR, intermediate between $S$ and $R$. Genetic crosses between different $O$ antigen groups (Mäkelä, 1966) have demonstrated that the $r f b$ cluster of genes, which is close to the his locus on the bacterial chromosome, contains all the information required for the synthesis of $O$ repeating units. If a Salmonella has the $r f b^{B}$ (of group B), its LPS has the group B specificity $4, I 2$, and if the $r f b$ is of group D $\left(r f b^{D}\right)$ the bacterium has the group D specificity $9, r 2$, etc.

\section{Structure of O side-chain}

$$
\begin{aligned}
& \left(\begin{array}{l}
\text { Abe } \\
\downarrow \\
\text { Man } \rightarrow \text { Rha } \rightarrow \text { Gal }
\end{array}\right)_{n} \\
& \left(\begin{array}{c}
\text { Tyve } \\
\downarrow \\
\text { Man } \rightarrow \text { Rha } \rightarrow \text { Gal }
\end{array}\right)_{n} \\
& (\overbrace{\text { Glu }}^{\overbrace{\text { Man } \rightarrow \text { Man } \rightarrow \text { Man }} \rightarrow \text { Man } \rightarrow \text { GNAc }})_{n} \text { ? }
\end{aligned}
$$

Group of Salmonella and the $\mathrm{O}$ antigenic specificity

\author{
Group B $(4,12)$ \\ Group D $(9,12)$ \\ Group C $(6,7)$
}

Fig. I. Schematic structure of the $O$ side-chains. According to Lüderitz, Jann \& Wheat (1968); the structure for the group C side-chain is only tentative (Fuller \& Staub, 1968). Abe = abequose, $\mathrm{Gal}=$ galactose, $\mathrm{Glu}=$ glucose, $\mathrm{GNAc}=N$-acetylglucosamine, $\mathrm{Man}=$ mannose, Rha $=$ rhamnose, Tyve $=$ tyvelose.

Some recent studies suggest that even in non- $\mathrm{R}$ forms possessing $\mathrm{O}$ side-chains the quantity of the $O$ side-chain material plays a role in virulence. The mouse virulence of an SR form, which has only one repeating unit per side-chain, is intermediate between the virulence of the $S$ and that of the $R$ form (Nakano \& Saito, I969). A highly virulent smooth Salmonella typhimurium was shown to possess about twice as many of the antigenic determinants 4,5 and $I 2$, measured by an immunological technique, as another smooth but avirulent $S$. typhimurium strain (Archer \& Rowley, I969). The ribose- and galactose-containing $\mathrm{T}$ I side-chains appear to confer only a slight degree of virulence on a $r f b$ mutant of $S$. typhimurium, much less than do the original $4,5,12$ side-chains, suggesting that the quality of the side-chain may also affect virulence (Valtonen, I969).

The purpose of this work was to make a systematic study of the possible effects on virulence of altering the quality of smooth-type $\mathrm{O}$ side-chains in a known virulent line of Salmonella typhimurium. The alteration was accomplished by genetic replacement of the original $r f b^{B}$ locus (that is $r f b$ of group B), which determines the structure of 4, I2-specific repeating units, with the $r f b^{D}$ locus of group D $(\mathrm{O}$ antigens 9,12$)$ or with $r f b^{C}$ locus of group $\mathrm{C}$ (O antigens 6,7 ). The $\mathrm{LD}_{50}$ value for mice was used as a measure of virulence in this work.

\section{METHODS}

Bacterial and phage strains. The bacterial strains with their main properties and origins are listed in Table I. The basic strain was SL 1027 of Salmonella typhimurium line LT2. This strain was originally obtained from Dr B. A. D. Stocker, Stanford University, California, U.S.A. The sH strains are kept in the collection of Professor P. H. Mäkelä, Central Public Health Laboratory, Helsinki, Finland. New mutations 

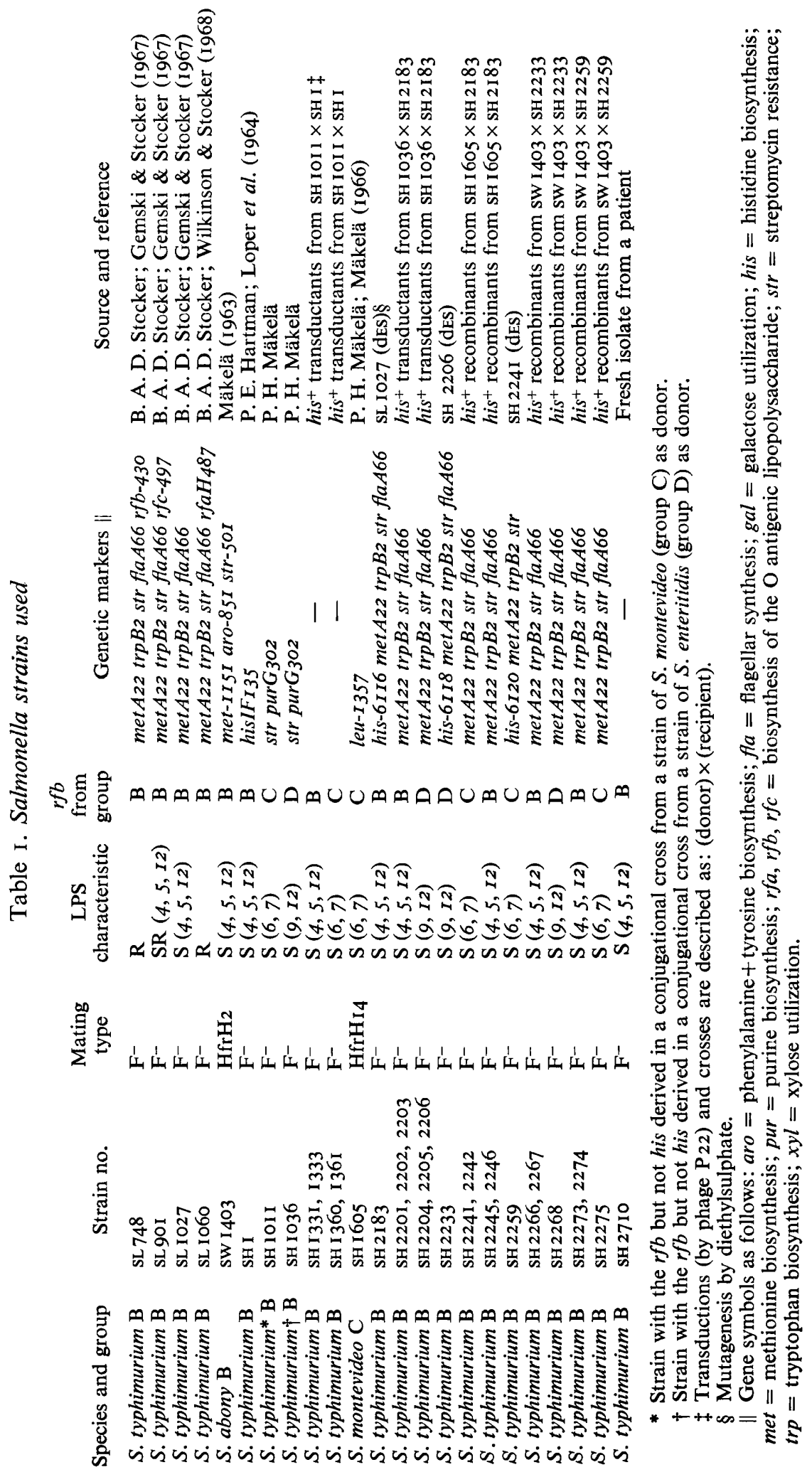
were induced by adding diethylsulphate (Io $\mathrm{mg}$. $/ \mathrm{ml}$.) to an overnight broth culture and incubating for $30 \mathrm{~min}$. at $37^{\circ}$. The culture was then diluted I:I00 in fresh medium and incubated overnight before plating on appropriate suboptimally supplemented media. The genetic donors were Hfr derivatives of Salmonella abony (Mäkelä, 1963) and $S$. montevideo. The gene symbols are explained in a footnote to Table $I$.

The S- and R-specific phages were originally obtained from Dr R. G. Wilkinson, University of Melbourne, Parkville, Australia. The following phages were used in this work: S-specific P22c2, 9NA, P22h; R-specific P22I, Br2, Ffm, Br60, C2I, S I3, $\phi X_{174}$ and 6SR; and FO which attacks both S and R bacteria (Wilkinson, I966; Wilkinson \& Stocker, 1968). Drops of phage lysates containing about $10^{8}$ plaqueforming units were applied to an agar plate previously spread with the bacterial strain to be tested.

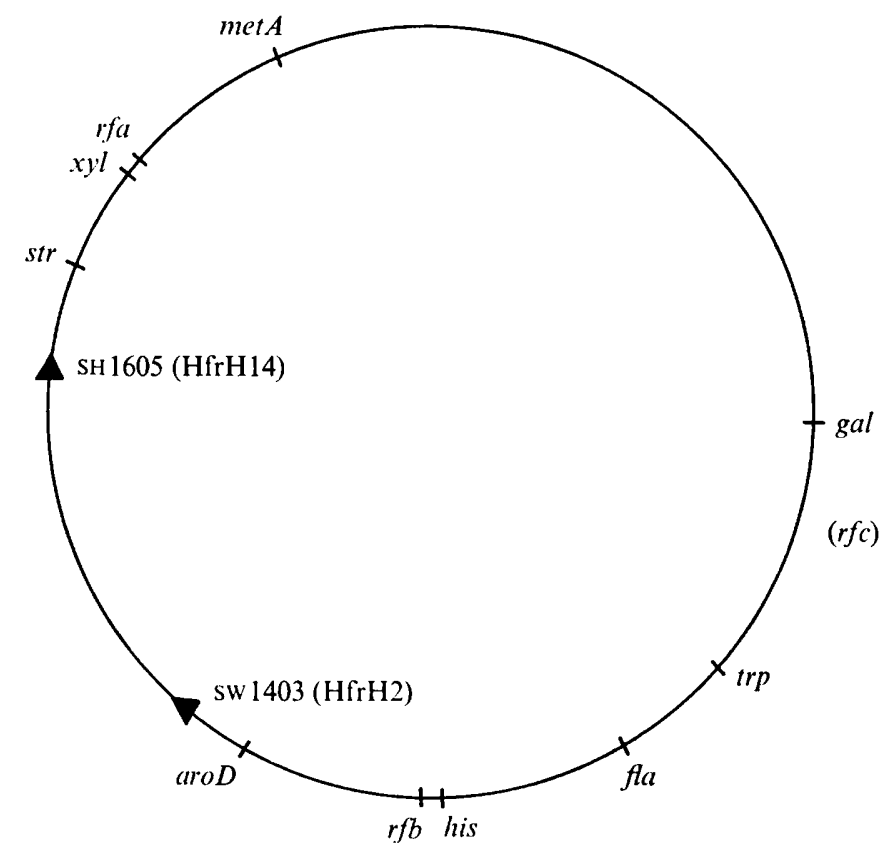

Fig. 2. A simplified chromosome map of Salmonella (according to Sanderson, 1967; Mäkelä \& Stocker, 1969). Positions not accurately known are indicated by symbols in parenthesis. The point of entry and direction of injection of donor chromosomes are indicated by arrows on the circle. For gene symbols, see footnote to Table $I$.

Phage P 22 was used for transduction experiments.

Media. Broth: Difco antibiotic medium 3 (I·75 g./100 ml.). Nutrient agar: broth solidified with $\mathrm{I} \cdot 3 \mathrm{~g}$. agar/100 ml. Selective media: Davis minimal medium (Lederberg, 1950) containing agar, $1.2 \%$; glucose, $0.2 \%$; required amino acids, $20 \mu \mathrm{g} . / \mathrm{ml}$.; streptomycin, I mg. $/ \mathrm{ml}$. where indicated. Suboptimally supplemented media: selective media with only $0.2 \mu \mathrm{g}$. $/ \mathrm{ml}$. of the amino acid for which mutants were selected (Hartman, Loper \& Serman, I960).

Genetic methods. In conjugation experiments, equal amounts of exponentially growing donor (Hfr) and recipient $\left(\mathrm{F}^{-}\right)$broth cultures, containing about $5 \times 10^{8}$ bacteria/ml., were mixed and incubated at $37^{\circ}$ for $2 \mathrm{~h}$. without shaking before plating on appropriate selective media (Mäkelä, I966). In transduction experiments, the phage 
( $\mathrm{IO}^{9}$ particles $/ \mathrm{ml}$.) was mixed with the exponentially growing recipient ( $\mathrm{IO}^{9}$ bacteria/ $\mathrm{ml}$. broth), and the mixture left for $10 \mathrm{~min}$. at $37^{\circ}$ with gentle shaking and then plated on the selective medium (Hartman et al. 1960). The recombinants or the transductants appearing after incubation for $48 \mathrm{~h}$. were restreaked on nutrient agar plates from which single colonies were picked for testing. The Hfr strains used and a schematic map of the Salmonella chromosome are given in Fig. 2.

Serological methods. $\mathrm{O}$ and $\mathrm{H}$ antigens were determined by slide agglutination in $4 \%$ saline and in antisera appropriately diluted with $0.2 \%$ saline. Anti-O sera were prepared by immunizing rabbits with saline suspensions of nutrient agarcultures of smooth strains kept at $100^{\circ}$ for $2.5 \mathrm{~h}$.; for anti-H sera the immunogen was a motile broth culture killed with formalin (Kauffmann, 1966).

Virulence test. The LD 50 value in mice was used to measure the virulence of the Salmonella strains (see Statistical methods). The SAw mice (Swiss Albino Webster strain) used in this work came from two different sources; line I from the State Serum Institute, Helsinki, Finland, and line II from the Department of Serology and Bacteriology, University of Helsinki. There was a small difference in their sensitivity to Salmonella typhimurium infection (see Results). Line I was used in only one set of experiments. Test animals of both sexes (aged 8 to 1o weeks, weighing between 22 and $25 \mathrm{~g}$.) were used.

The bacterial strain to be tested was grown in broth for $18 \mathrm{~h}$. (to early stationary phase, about $10^{9}$ bacteria/ml.), tenfold dilutions of the culture were made in $0.9 \%$ saline and the viable count was determined. Five consecutive dilutions $(0.5 \mathrm{ml}$. each) were injected intra peritoneally into five groups of ten mice kept in separate cages. Special care was taken to keep the cages physically separate and to prevent contamination in feeding and handling. The animal room was disinfected after each experiment.

Statistical methods. The LD 50 value was calculated from ro day survival according to Reed \& Muench (1938). In the standard assay, virulence of two recombinant classes from one cross (or transduction) possessing different $O$ antigens was compared. The statistical significance was calculated by forming a set of $2 \times 2$ tables from original data, according to the method of Mantel \& Haenszel (1959). As a rule, three such tables for three different dose levels were made as follows:

\section{Table of the $i^{\text {th. }}$ dose level}

$\begin{array}{llll}\text { No. of mice } & \text { Recombinant class I } & \text { Recombinant class II } & \text { Total } \\ \text { Surviving } & x_{11} & x_{21} & x_{\mathrm{i}} \\ \text { Dead } & N_{11}-x_{11} & N_{21}-x_{21} & N_{1}-x_{1} \\ \text { Sum } & N_{1 \mathrm{i}} & N_{21} & N_{\mathrm{i}}\end{array}$

where

$$
\begin{aligned}
& x_{1 \mathrm{i}} \text { and } x_{2^{\mathrm{i}}}=\text { numbers of surviving mice which had received the same } \\
& \text { dose }(a) \text { of recombinant class I bacteria }\left(x_{11}\right) \text { or recom- } \\
& \text { binant class II bacteria }\left(x_{2 i}\right) \text {, } \\
& N_{1 \mathrm{i}} \text { and } N_{2 \mathrm{i}}=\text { total numbers of mice inoculated with the same dose (a) } \\
& \text { of recombinant class I bacteria }\left(N_{11}\right) \text { or recombinant } \\
& \text { class II bacteria }\left(N_{21}\right) \text {, } \\
& x_{1}=x_{1 i}+x_{2 i}(=\text { total number of surviving mice), } \\
& N_{\mathrm{i}}=N_{11}+N_{21} \text { (= total number of infected mice). }
\end{aligned}
$$


If we consider the distribution of, say, $x_{11}$ conditionally on the marginal frequencies $N_{11}, N_{21}, x_{1}, N_{1}-x_{1}$, under $H_{0}$ (null hypothesis) it has the hypergeometric distribution $\bar{c}$. Under these circumstances $\chi^{2}$ should be computed as the ratio of the square of a deviation from its expected value to its variance (Mantel \& Haenszel, 1959).

Since,

and

$$
E\left(x_{11}\right)=x_{\mathrm{i}} N_{11} / N_{\mathrm{i}},
$$

then

$$
\operatorname{var}\left(x_{11}\right)=N_{11} N_{2 \mathrm{i}} x_{\mathrm{i}}\left(N_{\mathrm{i}}-x_{\mathrm{i}}\right) / N_{\mathrm{i}}^{2}\left(N_{\mathrm{i}}-\mathrm{I}\right) \text {, }
$$

$$
\frac{\left[\Sigma x_{11}-\Sigma E\left(x_{11}\right)\right]^{2}}{\Sigma \operatorname{var}\left(x_{11}\right)}
$$

has a $\chi^{2}$ distribution with one degree of freedom. The probability that a stated value of $\chi^{2}$ would be exceeded under $H_{0}$ is tabulated as $P$. The result is considered significant,

\begin{tabular}{|c|c|c|c|}
\hline & $4,5,12$ & 9,12 & Tota \\
\hline \multicolumn{4}{|c|}{ Dose level $\left(5 \times 10^{4}\right)$} \\
\hline Surviving & 22 & 28 & 50 \\
\hline Dead & 8 & 2 & IO \\
\hline Sum & 30 & 30 & 60 \\
\hline \multicolumn{4}{|c|}{ Dose level $\left(5 \times 10^{5}\right)$} \\
\hline Surviving & IO & 25 & 35 \\
\hline Dead & 20 & 5 & 25 \\
\hline Sum & 30 & 30 & 60 \\
\hline \multicolumn{4}{|c|}{ Dose level $\left(5 \times 10^{6}\right)$} \\
\hline Surviving & 2 & 9 & II \\
\hline Dead & 28 & $2 I$ & 49 \\
\hline Sum & 30 & 30 & 60 \\
\hline $\multicolumn{4}{|c|}{22+10+2-[50(30) / 60+35(30) / 60+\operatorname{II}(30) / 60]}^{2}$ \\
\hline
\end{tabular}
when $P \leqslant 0.01$ and highly significant with $P \leqslant 0.001$.

An example of the calculation from the original data in Table 2 is as follows:

Table 2. The lethal effect in mice of smooth 4, 5, 12 or smooth 9, I2 recombinants of Salmonella typhimurium

The table records the number of deaths in groups of 10 mice infected with tenfold dilutions of overnight broth cultures of $S(4,5,12)$ or $S(9,12)$ recombinants of $S$. typhimurium.

Strain

SH 220 I $S(4,5,12)$

$\mathrm{SH} 22 \mathrm{O} \mathrm{S}(4,5,12)$

$\mathrm{SH} 2203 \mathrm{~S}(4,5,12)$

SH $2204 \mathrm{~S}(9,12)$

SH $2205 \mathrm{~S}(9, \mathrm{I2})$

SH $2206 \mathrm{~S}(9,12)$

$\begin{array}{ccccc}5 \times \overbrace{10^{7 *}} & 5 \times 10^{6} & 5 \times 10^{5} & 5 \times 10^{4} & 5 \times 10^{3} \\ 10 & 10 & 5 & 5 & 0 \\ 10 & 8 & 6 & 1 & 0 \\ 10 & 10 & 9 & 2 & 0 \\ 8 & 7 & 1 & 0 & 0 \\ 8 & 5 & 2 & 2 & 0 \\ 10 & 9 & 2 & 0 & 0\end{array}$

* For SH $220 \mathrm{I}$ the actual doses were $6 \times \mathrm{ro}^{7}, 6 \times 10^{6}$, etc., and for $\mathrm{SH} 2203$ the corresponding doses were $4 \times 10^{7}, 4 \times 10^{6}$, etc. 


\section{RESULTS}

\section{Reliability of the virulence test}

Elimination of cross-infection. Control mice (I Io in all) were injected intraperitoneally with $0.5 \mathrm{ml}$. of $0.9 \% \mathrm{NaCl}$. Most of them were kept in their own cages placed between experimental cages, but a small number (15) were kept in groups of three in the same cages as infected animals. None of the control mice died during the Io day observation period.

Stability of the strain during virulence test. Bacterial stability was controlled in each experiment by testing 20 colonies for their $\mathrm{O}$ antigen serologically and with $\mathrm{S}$ - and $\mathrm{R}$-specific phages: 20 colonies were obtained both from the inoculum and from the cultures isolated from heart blood and intraperitoneal fluid of several dead mice. Most isolations were made within $\mathrm{I} h$. from the moment of death. No reversions from $\mathrm{R}$ to $\mathrm{S}$ forms or other changes in the $\mathrm{O}$ antigens were found after animal passage.

\section{Table 3. Time of death in mice after infection with virulent and avirulent strains of Salmonella typhimurium}

Cumulative deaths in groups of ten mice injected intraperitonelly with $0.5 \mathrm{ml}$./mouse of tenfold dilutions of overnight broth cultures of virulent and avirulent strains of Salmonella typhimurium.

\begin{tabular}{|c|c|c|c|c|c|c|c|c|c|c|c|c|c|}
\hline \multirow{3}{*}{$\begin{array}{l}\text { Days } \\
\text { after } \\
\text { inject- } \\
\text { ion }\end{array}$} & \multicolumn{12}{|c|}{ Number of mice dead after injection with } & \multirow{2}{*}{$\begin{array}{l}\text { R) } \\
\text { //mouse) }\end{array}$} \\
\hline & \multicolumn{4}{|c|}{$\begin{array}{c}\text { SH } 2183 \mathrm{~S}(4,5,12) \\
\text { Dose (bacteria/mouse) }\end{array}$} & \multicolumn{5}{|c|}{$\begin{array}{c}\text { SH } 27 \text { Io S }(4,5,12) \\
\text { Dose (bacteria/mouse) }\end{array}$} & \multicolumn{3}{|c|}{$\begin{array}{c}\text { SL } 748(\mathrm{R}) \\
\text { Dose(bacteria/mouse) }\end{array}$} & \\
\hline & $5 \times 10^{7}$ & $5 \times 10^{6}$ & $5 \times 10^{5}$ & $5 \times 10^{4}$ & $5 \times 10^{3}$ & $5 \times 10^{5}$ & $5 \times 10^{4}$ & $5 \times 10^{3}$ & $5 \times 10^{2}$ & 50 & $5 \times 10^{8}$ & $5 \times 10^{7}$ & $5 \times 10^{6}$ \\
\hline 0 & 0 & 0 & 0 & 0 & 0 & 0 & 0 & 0 & 0 & 0 & 0 & 0 & 0 \\
\hline I & 9 & I & 0 & 0 & 0 & I & 0 & 0 & 0 & 0 & 8 & 0 & 0 \\
\hline 2 & I0 & 4 & I & 0 & 0 & 2 & 0 & I & I & 0 & 8 & 2 & 0 \\
\hline 3 & 10 & 9 & I & I & 0 & 6 & 0 & I & I & 0 & 9 & I & 0 \\
\hline 4 & 10 & 9 & 2 & I & 0 & 8 & 3 & 3 & 6 & 0 & 10 & 2 & o \\
\hline 5 & IO & 9 & 3 & I & 0 & 10 & 5 & 5 & 7 & 3 & 10 & 3 & 0 \\
\hline 6 & 10 & IO & 5 & 2 & 0 & IO & 5 & 5 & 7 & 3 & 10 & 3 & 0 \\
\hline 7 & IO & IO & 5 & 2 & 0 & 10 & 9 & 6 & 9 & 3 & 10 & 3 & 0 \\
\hline 8 & IO & I0 & 5 & 4 & 0 & 10 & 9 & 8 & 9 & 3 & 10 & 5 & 0 \\
\hline 9 & IO & Io & 6 & 4 & 0 & 10 & 9 & IO & 9 & 5 & 10 & 5 & 0 \\
\hline 10 & IO & IO & 6 & 5 & 0 & 10 & 9 & I0 & 9 & 5 & 10 & 5 & 0 \\
\hline 30 & 10 & 10 & 7 & 5 & 0 & 10 & 10 & IO & 9 & 7 & 10 & 5 & 0 \\
\hline
\end{tabular}

The LD 50 value calculated from the Io day survival.

Choice of the observation period. For obvious reasons a relatively short observation period was desirable. Essential information does not seem to be lost by our choice of the Io day period as compared with the conventional 30 day experiment, because over $90 \%$ of the deaths in 30 day experiments occur during the first io days (Table 3 ). The shorter period may have an advantage in recording deaths due to the original inoculum since it is not likely to include deaths from secondary infection from cage mates.

Choice of the Salmonella strain. We wanted to use Salmonella typhimurium LT 2 line as a basic strain, because it is genetically well characterized. The problem was that the 
LT 2 line has a fairly low virulence compared with many $S$. typhimurium strains isolated from clinical specimens, e.g. SH27Io in Table $3, \mathrm{LD}_{50}<\mathrm{IO}^{2}$. The $\mathrm{LD}_{50}$ values of SH I and SL 1027 used in this work were about $10^{5}$, while several other smooth LT 2 lines were even less virulent $\left(\mathrm{LD}_{50}>10^{6}\right)$. New auxotrophic mutants isolated from SL 1027 after mutagen treatment had often lost their virulence, and for this reason the virulence of each new mutant was checked before use. In further tests some of the new avirulent mutants were still smooth, but their loss of virulence could not be clearly correlated with the known auxotrophic mutations because their prototrophic revertants were still avirulent. The same phenomenon has been described earlier (Herzberg, 1962).

Reproducibility of the LD 50 values in the same mouse line was good (Table 4).

Table 4. LD 50 values for smooth Salmonella typhimurium strain LT2 and its $S R$ or $R$ mutants

\begin{tabular}{|c|c|c|c|c|c|c|c|}
\hline \multirow{2}{*}{$\begin{array}{c}\text { Strain } \\
\text { no. }\end{array}$} & \multirow{2}{*}{$\begin{array}{l}\text { Somatic } \\
\text { antigen }\end{array}$} & \multirow{2}{*}{$\begin{array}{l}\text { Mutant } \\
\text { LPS } \\
\text { genes }\end{array}$} & \multicolumn{2}{|c|}{ SAW mice line I } & \multicolumn{3}{|c|}{ SAW mice line II } \\
\hline & & & (i) & (ii) & (iii) & (iv) & (v) \\
\hline SL 1027 & $\mathrm{~S}(4,5,12)$ & - & $4 \times 10^{4}$ & $3 \times 10^{4}$ & $\mathrm{I} \times 10^{5}$ & $5 \times 10^{5}$ & $1 \times 10^{\circ}$ \\
\hline SL9OI & $\mathrm{SR}(4,5,12)$ & $r f c$ & $1 \times 10^{6}$ & $2 \times 10^{8}$ & - & - & - \\
\hline SL 748 & $\mathbf{R}$ & $r f b$ & $5 \times 10^{7}$ & $1 \times 10^{8}$ & $1 \times 10^{8}$ & - & - \\
\hline SL 1060 & $\mathbf{R}$ & $r f a H$ & $2 \times 10^{8}$ & $1 \times 10^{8}$ & - & - & - \\
\hline
\end{tabular}

(i) etc. refer to different experiments.

Effect of $S \rightarrow R$ variation on virulence in the chosen experimental conditions. The $\mathrm{LD}_{50}$ value of the smooth $\mathrm{LT}_{2}$ line was about $10^{5}$, while the $\mathrm{LD}_{50}$ values of rough forms $(r f b, r f a H)$ were about $10^{8}$ (Table 4 ). The difference between $\mathrm{S}$ and $\mathrm{R}$ forms, therefore, was only about a thousandfold as compared to the almost millionfold difference seen between $\mathrm{S}$ and $\mathrm{R}$ forms when starting from highly virulent Salmonella strains (Arkwright, I927). However, in spite of this narrow scale, the virulence of the semirough mutant $(r f c)$ with only one repeating unit per side-chain was clearly intermediate (LD $50 \sim 10^{6}$ ) between the virulence of the smooth and the $\mathrm{R}$ forms. There was no difference between the $r f b$ and the $r f a H$ mutants, agreeing with previous observations on different R mutants (Nakano \& Saito, 1969; Edebo \& Normann, 1970). Although both mutants were avirulent, they could be isolated as pure cultures from the heart blood of dead mice, indicating that when injected in large enough amounts they were also capable of causing infections. The endotoxin (LPS) effect seems to be lethal only at very high dose levels ( $>10^{8}$ bacteria/mouse): some deaths were observed on the first day after intraperitoneal injection of about $10^{9}$ heat-killed bacteria/mouse, but there were no deaths after a dose of about $10^{8}$.

\section{The effect of 9, 12-specific side-chains}

The $r f b$ locus of Salmonella typhimurium determining 4, I2 specificity was replaced through $\mathrm{P}_{22}$ transduction by the $r f b$ locus of $S$. enteritidis determining $9, I 2$ specificity. Phage P 22 grown on the $h i s^{+}$9, I2 donor SH 1036 was applied to the his ${ }^{-}$4, 5, I2 virulent $\left(\mathrm{LD}_{50}=\mathrm{IO}^{5}\right)$ recipient $\mathrm{SH}_{2 \mathrm{I}} 83$; some of the his ${ }^{+}$transductants had the $\mathrm{O}$ antigens $9, I 2$ indicating that they had inherited the $r f b^{D}$ locus of the donor, while the remaining his $^{+}$transductants were antigenically $4,5, \mathbf{I 2}$. The virulence of three 
transductants from both classes was determined (Tables 2, 5). The LD 50 values of three $h^{+}{ }^{+}$4, 5, 12 transductants were about $10^{5}$, like that of the recipient, while the 9, 12 transductants showed slightly reduced virulence $\left(\operatorname{LD}_{50} \sim 10^{6}\right)$. The difference between these two recombinant classes was highly significant $(P<0.001)$. As a control, a his mutant was made from one 9,12 transductant and was used as a recipient in a conjugational cross with an avirulent $\left(\operatorname{LD}_{50}=10^{8}\right) 4,5, I 2 S$. abony Hfr strain. It was very unlikely that the avirulence loci in S. abony (Krishnapillai \& Baron, 1964) would have been transferred in this conjugation, because of the his ${ }^{+}$selection and the direction of chromosome injection by the donor (Fig. 2). The LD 50 values of two his $^{+} 4,5,12$ recombinants obtained in this cross were about $10^{5}$, indicating a restoration of the original virulence together with the 4, 5, I2 specificity. The virulence of a his $^{+}$9, I2 recombinant was unchanged ( $\left.\operatorname{LD}_{50}>10^{6}\right)$. It thus appears that 4, 5, I2specific side-chains confer a slightly higher degree of mouse virulence on a $S$. typhimurium strain than do 9, I2-specific side-chains.

Table 5. LD 50 values of smooth Salmonella typhimurium strains with the $O$ specificity 4, 5, 12 or 9, 12

Origin of transductants or recombinants

$\overbrace{\begin{array}{c}\text { Donor } 1036 \\ \left(\text { his }^{+}, 9, I 2\right)\end{array} \times \text { P22 transduction }_{\left(\text {his }^{-}, 4,5, I 2\right)}^{\text {SH 21 83 }}}^{\text {Recipient }}$

Selection for $\mathrm{his}^{+}$

\begin{tabular}{lll}
\multicolumn{2}{c}{ Back-cross (conjugation) } \\
SW 1403 & $\times$ & SH 2233 \\
is $^{+}, 4,5, I 2$ & & $h^{-}, 9, I 2$
\end{tabular}

Selection for $h i s^{+}$

\begin{tabular}{|c|c|c|}
\hline \multicolumn{3}{|c|}{ LD 50 values } \\
\hline Strain no. & \multicolumn{2}{|c|}{ O specificity } \\
\hline & $4,5,12$ & 9,12 \\
\hline $\begin{array}{l}\text { Recipient } \\
\text { SH } 2183\end{array}$ & $1 \times 10^{5}$ & \\
\hline Transducte & & \\
\hline SH 2201 & $2 \times 10^{5}$ & - \\
\hline SH 2202 & $4 \times 10^{5}$ & 一 \\
\hline SH 2203 & $1 \times 10^{5}$ & - \\
\hline SH 2204 & - & $3 \times 10^{6}$ \\
\hline SH 2205 & - & $3 \times 10^{6}$ \\
\hline SH 2206 & - & $1 \times 10^{6}$ \\
\hline Recipient & & \\
\hline SH 2233 & 一 & $2 \times 10^{6}$ \\
\hline Recombine & & \\
\hline SH 2266 & $\mathrm{I} \times 10^{5}$ & 一 \\
\hline SH 2267 & $3 \times 10^{5}$ & 一 \\
\hline SH 2268 & - & $4 \times 10^{6}$ \\
\hline
\end{tabular}
SH 2233 (his ${ }^{-}$, 9, I2) was derived from transductant SH 2206.

The effect of 6, 7-specific side-chains

To convert the type $4,5,12$ Salmonella typhimurium to type 6,7 , conjugation was first used instead of transduction, because there were no suitable transducing phages available for such an intergroup system. The results were later confirmed with 6,7 and $4,5, I 2$ transductants, obtained in the round about way described below.

The same virulent his ${ }^{-}$4, 5, I2 Salmonella typhimurium recipient (SH 2183) as before was crossed with an avirulent $\left(\mathrm{LD}_{50}=\mathrm{IO}^{8}\right) \mathrm{S}$. montevideo donor (Hfr) strain and his $^{+}$ recombinants were selected. As expected (Mäkelä, 1966), about $80 \%$ were serologically 6,7 and had therefore inherited the $r \mathrm{fb}^{C}$ cluster from the $S$. montevideo donor, while the remaining $20 \%$ were $4,5,12$ and had thus retained the original $r f^{B}$ locus. Virulence of two his ${ }^{+}$6,7 and two his ${ }^{+} 4,5,12$ recombinants was determined (Table 6). These recombinants were also trp- like the recipient, which put a limit on the amount 
of donor material on one side of the his marker (see Fig. 2); on the other side the 6, 7 recombinants could have inherited a larger fraction of the donor chromosome. This fraction was probably quite small, however, and the two recombinant classes differed from each other mainly in the $r f b$ region, because in intergroup crosses only short chromosome fragments are usually incorporated (Stocker \& Mäkelä, 197I). The two recombinants with 4, 5, I2 specificity were as virulent as the recipient (LD 50 $\left.\sim 10^{5}\right)$, while the 6,7 recombinants were avirulent $\left(\operatorname{LD}_{50}=10^{7}\right.$ to $\left.10^{8}\right)$. The difference between the $\mathrm{LD}_{50}$ values of these two recombinant classes was highly significant $(P<0.001)$. As a further check it was tested whether the virulence of the 6,7 recombinant could be restored to the level of the parent, by reintroducing the $r f b^{B}$ locus determining $4,5,12$ specificity, to a his ${ }^{-}$mutant of the 6,7 recombinant. This 'backcross' was performed using the same S.abony Hfr donor as with the 9, 12 transductants above. The $\mathrm{LD}_{50}$ values of two his ${ }^{+} 4,5,12$ recombinants were between $10^{5}$ to $10^{6}$, while the $\mathrm{LD}_{50}$ value of a his $^{+} 6,7$ recombinant was unchanged $\left(10^{8}\right)$, strongly indicating that the $4,5,12$ side-chains had restored virulence to these recombinants (Table 6). The fact that the original $\mathrm{LD}_{50}$ value of $10^{5}$ was not quite achieved could be due to the manipulations (mutagenesis and crossing), which the strains had experienced before virulence testing.

Table 6. $L D 50$ values of smooth Salmonella typhimurium strains with the $O$ specificity $4,5,12$ or 6,7

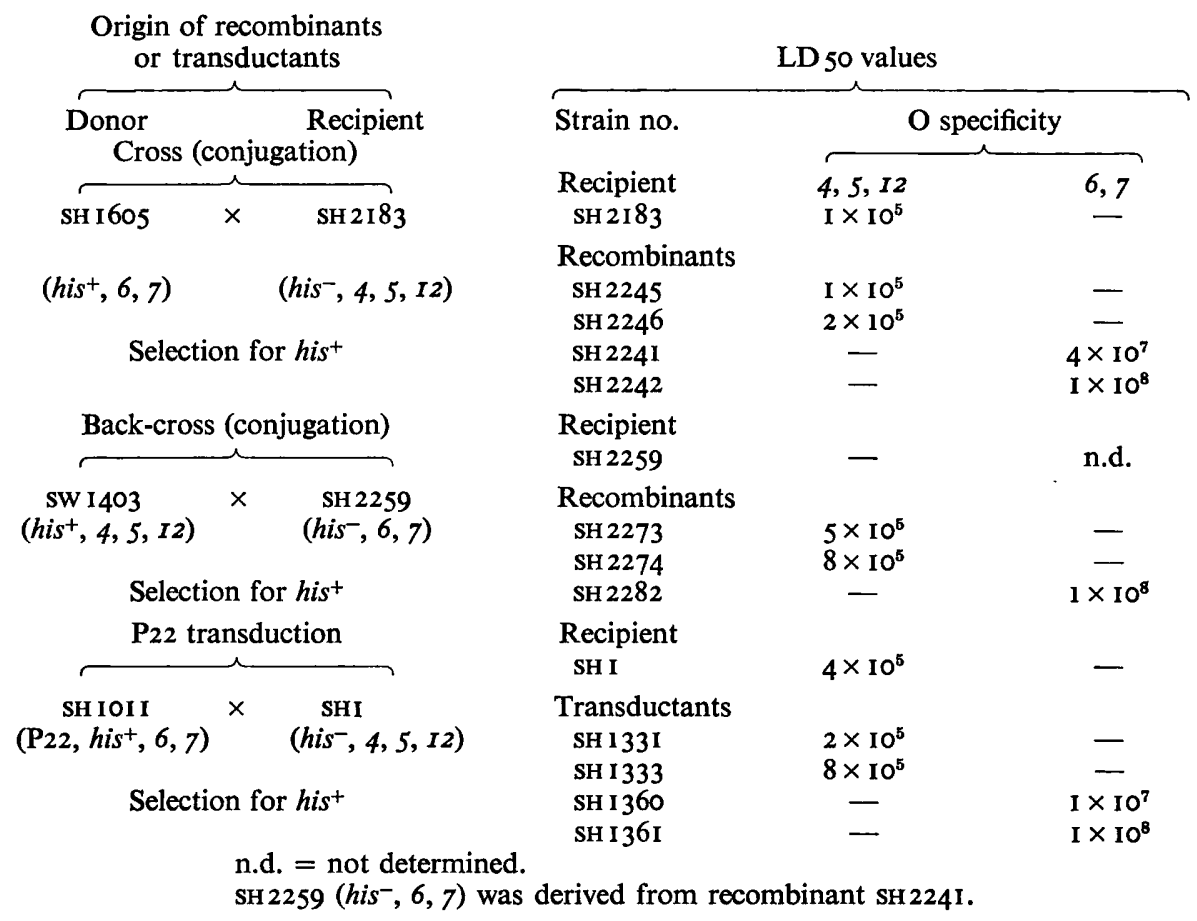

It seems very probable, therefore, that the loss of virulence in the 6,7 recombinants was due to the presence of the $r f b^{C}$ locus, although possible 'avirulence loci' (Krishnapillai \& Baron, 1964) closely linked to his and present in the avirulent 
Salmonella montevideo donor, could not be excluded. Because of the drastic reduction of virulence it was felt desirable to limit the amount of genetic material transferred along with his. This could be achieved in transduction, but the available transducing phage $\mathrm{P}_{22}$ would not attack 6,7 bacteria. A P 22 lysate could, however, be prepared by induction of a strain of $S$. typhimurium which was lysogenic for $\mathrm{P} 22$ and which had been given $r f b^{C}$ in a conjugational cross with $S$. montevideo as the Hfr donor. The lysate had a fairly low titre, and transduction did not succeed with SH 2 I 83 as a recipient. It did succeed, however, with another his $-S$. typhimurium strain LT 2 (SH I). The $\mathrm{LD}_{50}$ values of two his $^{+} 4,5,12$ transductants were again $10^{5}$ to $10^{6}$ like those of the recipient, while the corresponding values of $h i s^{+} 6,7$ transductants were $10^{7}$ to $10^{8}$ (see Table 6).

\section{DISCUSSION}

This work has demonstrated that different $\mathrm{O}$ side-chains confer different degrees of mouse virulence on a basically virulent Salmonella typhimurium. Salmonella typhimurium with the original 4, 5, I2-specific side-chains is slightly more virulent than the same strain with $9, I 2$ specificity, and this is clearly more virulent than the same $S$. typhimurium strain with 6,7 side-chains. Yet all the strains studied were smooth according to all available criteria: sensitivity to S-specific phages and resistance to $\mathrm{R}$-specific phages; S-type agglutination with specific anti-O sera but no agglutination with $4 \%(w / v)$ saline or with antirough sera.

In each experiment the virulence of several sister recombinants was compared in order to keep the strains as isogenic as possible, the only difference between them being in the $O$ side-chain. When comparing the $9, I 2$ and $4,5, I 2$ strains this purpose appears to have been well achieved. The strains were prepared by transduction, so that the non-identical fraction of the genome of the two transductant classes was less than I \% (the amount of DNA transferred in transduction is of the order of $1 \%$ of the total chromosome; both transductant classes also had common areas in the histidine locus received from the donor). The 6,7 strains were prepared by conjugation and by transduction. In both cases the result was the same, low virulence always accompanying the 6,7 characteristic and high virulence accompanying the 4, 5, I2 specificity. Combining the data from the transduction and the conjugation analyses, four strains of 9,12 specificity were all less virulent than six sister $4,5,12$ strains and five strains of 6,7 specificity were clearly less virulent than seven sister 4, 5, 12 strains. There is strong evidence in these results for the association of virulence with the quality of the $\mathrm{O}$ side-chain as determined by the $r f b$ locus. Other genes determining virulence and closely linked with the $r f b$ locus are not excluded but if they exist their number is limited.

A limitation of the action of foreign (groups $\mathrm{C}$ or $\mathrm{D}$ ) genetic material in the group $\mathrm{B}$ genome is also possible. Again the effect, if present, must be limited to $r f b$ and a few other closely linked genes. If this impairment occurred, it was not large enough to make the strains detectably non-smooth, although searching criteria for smoothness were applied (Lindberg, Sarvas \& Mäkelä, 1970). Pleiotropic effects of the foreign $r f b$ genes are also conceivable but improbable.

We do not know how the quality of the $\mathrm{O}$ side-chain affects virulence. There are at least two possibilities: $(a)$ the quality of the monosaccharide constituents of the different types of $\mathrm{O}$ side-chains is of major importance, or $(b)$ the main factor is the 
degree of exposure of the deeper layers of the cell wall including the LPS core, resulting from differences in length and/or arrangement of the $\mathrm{O}$ side-chains of different specificities.

The quality of the monosaccharides is very similar in the repeating units of the 4,12 and 9,12 side-chains. The only difference lies in the dideoxyhexose which forms an immunodominant side branch in the main chain (Fig. I), and which is abequose in $4, I 2$ and tyvelose in $9, I 2$. It is not easy to understand why the mouse reacts differently to the two sorts of dideoxyhexoses. The 4,I2 strains used in this work also had factor 5 , which corresponds to an $O$-acetyl group on the abequose (Hellerqvist et al. 1968), but in another study isogenic Salmonella typhimurium strains with and without factor 5 were found to be equally virulent, indicating that this factor does not affect virulence (V. V. Valtonen \& P. H. Mäkelä, in preparation). The 6, 7 side-chains on the other hand are very different, lacking both the deoxyhexose rhamnose and the dideoxyhexose.

From the point of view of the host in relation to the observed differences in virulence, two mechanisms can be suggested: resistance could be based either on an immunological mechanism or associated with phagocytosis. The 6, 7-specific sidechains may be more immunogenic than the 4, 5, I2 side-chains, or the mice may have 'natural antibodies' against 6,7 antigen giving better protection against a Salmonella strain with 6,7 specificity. If these were the main causes of the observed differences in virulence, we have to assume that a 9, I2-specific LPS is also more immunogenic than the 4, (5), 12 LPS, or that the mice possess more 'natural antibodies' against 9,12 than $4,(5), 12$ determinants. We have studied the role of the immune response in infection with the transductant strains used in this work and the results are to be published soon.

There are several reports which have shown that avirulent Salmonella strains are killed more rapidly by phagocytic cells than are virulent ones (Furness, I958; Biozzi et al. 1964; Fauve, 1964; Ushiba, 1965). The mechanism by which virulent strains can resist phagocytosis is unknown, but it seems probable that the structure of the LPS is of major importance in this respect. An obvious experimental approach would be to determine whether the 4, 5, I2 LPS is more 'antiphagocytic' than 9, I2 or 6, 7 LPS.

Similar differences in virulence associated with cell-wall polysaccharides have also been found in Pneumococcus and Escherichia coli. MacLeod \& Krauss (1950) found that both the amount and the quality of the capsular polysaccharide have an effect on the virulence of Pneumococcus. The capsular polysaccharides are known to be 'antiphagocytic' substances. The capsular polysaccharide of type VII Pneumococcus is a particularly efficient antiphagocytic substance; it contains L-rhamnose and other deoxysugars (How, Brimacombe \& Stacey, 1964). Medearis and co-workers (I968) have found that the sugar composition of the cell wall strongly affects the virulence of $E$. coli. Apart from a rough mutant they also used an apparently smooth mutant of $E$. coli O-II I strain lacking only a terminal dideoxyhexose colitose in its LPS, and found this to be clearly less virulent than the parent strain. Loss of virulence in this mutant was accompanied by diminished resistance to phagocytosis. The present work with Salmonella strains has clear analogies with these observations. The 4, 5, I2 and 9,12 side-chains, which confer stronger mouse virulence than the 6,7 side-chains, also contain both L-rhamnose and a dideoxyhexose (abequose or tyvelose respectively), while the 6,7 side-chain does not contain either. One is tempted to suggest that 
these lipophilic deoxy- or dideoxysugars, which are rare in nature, are also important determinants of anti-phagocytic activity and thus of bacterial virulence.

I thank Professor P. Helena Mäkelä for her help in preparing the manuscript and also for help with materials, Professor O. Miettinen for suggesting the statistical significance test applied, Miss Marianne Hovi for preparing some of the strains, and Mrs Aila Åkerlund and Mrs Eila Tikkanen for their technical assistance. This work was supported by grants from the Sigrid Jusélius Foundation to Professor Mäkelä and from the Emil Aaltonen Foundation.

\section{REFERENCES}

ARCHER, J. R. \& RowLEY,D. (1969). A quantitative comparison of the antigenic structure of a virulent and an avirulent strain of Salmonella typhimurium. Immunology 17, 551-558.

ARKWright, J. A. (1927). The value of different kinds of antigen in prophylactic 'enteric' vaccines. Journal of Pathology and Bacteriology 30, 345-364.

Biozzi, G., Le Minor, L., Stiffel, C., Mouton, D. \& Daoulas, F. (1964). Correlation between virulence and phagocytosis of genetic recombinant between Escherichia coli and Salmonella typhimurium. Nature, London 202, 819-820.

EDEBo, L. \& NormanN, B. (1970). Virulence and immunogenicity of mutant strains of Salmonella typhimurium. Acta pathologica et microbiologica scandinavica 78 B, 75-84.

Fauve, M. R. (1964). Résistance cellulaire à l'infection bactérienne. Annales de l'Institut Pasteur, Paris 107, 472-483.

Fuller, N. A. \& Staub, A. M. (1968). Immunochemical studies on Salmonella 13. Chemical changes appearing on the specific polysaccharide of $S$. cholerae suis $\left(6_{2}, 7\right)$ after its conversion by phage 14 $(6,7)$. European Journal of Biochemistry 4, 286-300.

FURNESS, G. (1958). Interaction between Salmonella typhimurium and phagocytic cells in cell culture. Journal of Infectious Diseases ro3, 272-277.

Gemski, P. JUn. \& Stocker, B. A. D. (1967). Transduction by bacteriophage $\mathbf{P} 22$ in non-smooth mutants of Salmonella typhimurium. Journal of Bacteriology 93, 1588-1597.

Hartman, P. E., Loper, J. C. \& Serman, D. (1960). Fine structure mapping by complete transduction between histidine-requiring Salmonella mutants. Journal of General Microbiology 22, 323-353.

Hellerqvist, C. G., Lindberg, B., Svensson, S., Holme, T. \& Lindberg, A. A. (1968). Structural studies on the O-specific side-chains of the cell wall lipopolysaccharide from Salmonella typhimurium 395 Ms. Carbohydrate Research 8, 43-55.

HERZBERG, M. (1962). Living organisms as immunizing agents against experimental salmonellosis in mice. I. Virulence of auxotrophic mutants. Journal of Infectious Diseases III, 192-203.

How, M. J., BRimacombe, J. S. \& STACEY, M. (1964). The pneumococcal polysaccharides. Advances in Carbohydrate Research 19, 303-358.

Kauffmann, F. (1966). The Bacteriology of Enterobacteriaceae. Copenhagen: Munksgaard.

KrishNapillai, V. \& Baron, L. S. (1964). Alterations in the mouse virulence of Salmonella typhimurium by genetic recombination. Journal of Bacteriology 87, 598-605.

LEDERBERG, J. (1950). Isolation and characterization of biochemical mutants of bacteria. Methods in Medical Research 3, 5-22.

Lindberg, A. A., Sarvas, M. \& Mäkelä, P. H. (1970). Bacteriophage attachment to the somatic antigen of Salmonella: effect of $O$-specific structures in leaky $R$ mutants and $S, T I$ hybrids. Infection and Immunity 1, 88-97.

LiNGelsheIM, V. (1913). Zur Frage der Variation der Typhusbacillen und verwandter Gruppen. Zentralblatt für Bakteriologie, Parasitenkunde, Infektionskrankheiten und Hygiene (Abteilung I Originale) 68, 577-582.

Loper, J. C., Grabnar, M., Stahl, R. C., Hartman, Z. \& Hartman, P. E. (1964). Genes and proteins involved in histidine biosynthesis in Salmonella. Brookhaven Symposia in Biology 17, 15-52. 
LÜDERITZ, O., JANN, K. \& WHEAT, R. (1968). Somatic and capsular antigens of Gram-negative bacteria. In Comprehensive Biochemistry, vol. 26 A, pp. 105-228. Edited by M. Florkin and E. H. Stotz. Amsterdam: Elsevier.

MacLeod, C. M. \& Krauss, M. R. (1950). Relation of virulence of pneumococcal strains for mice to the quantity of capsular polysaccharide formed in vitro. Journal of Experimental Medicine 92, $1-9$.

Mantel, N. \& HaEnszel, W. (1959). Statistical aspects of the analysis of data from retrospective studies of disease. Journal of The National Cancer Institute 22, 719-748.

Medearis, D. N. Jun., Camitta, B. M. \& Heath, E. C. (I968). Cell wall composition and virulence in Escherichia coli. Journal of Experimental Medicine 128, 399-414.

MÄKELÄ, P. H. (1963). Hfr males in Salmonella abony. Genetics 48, 423-429.

MäKELÄ, P. H. (1966). Genetic determination of the $O$ antigens of Salmonella groups B $(4,5,12)$ and $\mathrm{C}_{1}(6,7)$. Journal of Bacteriology 9x, I I $15-1$ I 25.

MäkeLÄ, P. H. \& Stocker, B. A. D. (1969). Genetics of polysaccharide biosynthesis. Annual Review of Genetics 3, 291-322.

NaKano, M. \& SaITo, K. (1969). Chemical components in the cell wall of Salmonella typhimurium affecting its virulence and immunogenicity in mice. Nature, London 222, 1085-1086.

ReED, L. G. \& MueNCH, H. (1938). A simple method of estimating fifty per cent end-points. American Journal of Hygiene 27, 493-497.

Roantree, R. J. (1967). Salmonella $\mathrm{O}$ antigens and virulence. Annual Review of Microbiology 2r, 443-466.

SANDERSON, K. E. (1967). Revised linkage map of Salmonella typhimurium. Bacteriological Reviews 3I, 354-372.

STOCKER, B. A. D. \& MäKELÄ, P. H. (I97I). Genetic aspects of biosynthesis and structure of Salmonella lipopolysaccharide. In Microbial Toxins, vol. 4. Edited by S. J. Ajl. New York: Academic Press.

UshiBA, D. (1965). Two types of immunity in experimental typhoid: 'cellular immunity' and 'humoral immunity'. Keio Journal of Medicine 14, 45-61.

VALTONEN, V. V. (1969). Virulence of Salmonella strains with a reduced amount of O antigen. Journal of General Microbiology 57, xxviii.

WiLkInson, R. G. (1966). Rough Mutants of Salmonella typhimurium. Ph.D. Thesis, University of London,

WiLkinson, R. G. \& Stocker, B. A. D. (1968). Genetics and cultural properties of mutants of Salmonella typhimurium lacking glucosyl or galactosyl lipopolysaccharide transferases. Nature, London 217, 955-957. 